\title{
Host-specific morphologies but no host races in the commensal bivalve Neaeromya rugifera
}

\author{
Jingchun $\mathrm{Li}^{\mathrm{a}}$ and Diarmaid Ó Foighil \\ Museum of Zoology, Department of Ecology and Evolutionary Biology, \\ University of Michigan, Ann Arbor, Michigan 48109, USA
}

\begin{abstract}
Speciation by host shift is one of the explicit models of ecological speciation. A prerequisite of this model is the formation of host races (sympatric populations that show host-specific genetic structuring and phenotypes). Many members of the diverse marine bivalve superfamily Galeommatoidea have obligate commensal relationships with invertebrate hosts. Some species have the ability to occupy multiple host species, thereby providing potential opportunities to test for the formation of host races. The Northeast Pacific galeommatoidean Neaeromya rugifera attaches to two strikingly different hosts: the blue mud shrimp Upogebia pugettensis and the polychaete sea mouse Aphrodita spp. We tested if this host difference has resulted in the formation of host races using shell morphologies and genetic markers. We found that populations from different hosts differ significantly in shell morphology. However, based on mitochondrial makers, N. rugifera showed no distinct host-specific genetic structuring, indicating the existence of a panmictic population. We conclude that the host-specific morphologies these clams exhibit may reflect ecophenotypic plasticity rather than the existence of host races, but this needs to be corroborated with additional genetic data and larger sample sizes. The pronounced conchological variation within $N$. rugifera calls for further investigation of its taxonomic relationship with its poorly studied, but morphologically similar, sympatric congener Neaeromya compressa.
\end{abstract}

Additional key words: Aphrodita, Galeommatoidea, phenotypic plasticity, Upogebia

Galeommatoidean clams are a poorly studied superfamily of minute, morphologically diverse bivalves (Coan \& Valentich-Scott 2012). Their outsized role in marine alpha biodiversity has become apparent over the last decade with the application of comprehensive sampling methodologies that effectively gather taxa whose members are small in body size (Bouchet et al. 2002). Although members of a given species are typically rare, galeommatoideans collectively exhibit among the highest levels of bivalve alpha diversity in both neontological (Bouchet et al. 2002; Paulay 2003) and paleontological (Schneider \& Hochleitner 2006) surveys. Consequently, this superfamily is now recognized as a "megadiverse" group (Paulay 2003).

Galeommatoidea is also notable for containing large numbers of commensal species in addition to free-living taxa. The spectrum of host taxa used by the commensals includes crustaceans, holothuroids,

\footnotetext{
${ }^{\mathrm{a}}$ Author for correspondence.

E-mail: jingchun@umich.edu
}

echinoids, cnidarians, and polychaetes, among others (Boss 1965; Mikkelsen \& Bieler 1989; Morton \& Valentich-Scott 1989; Jespersen et al. 2004). Commensals either attach directly to their hosts or live in or around host burrows, and individual clam species may associate with single or multiple host species. The prevalence of commensal life histories among galeommatoideans raises the possibility that this life history has contributed to their exceptional species diversity. Specifically, one may ask whether speciation by host shift occurred frequently in this group and accelerated its diversification.

Host shifts in symbiotic systems provide unique opportunities for ecological divergent selection to occur (Simon et al. 2003). In a symbiotic association, the host can be viewed as a microhabitat, and the symbiont often evolves specialized adaptations to a specific host (Reznick \& Ghalambor 2001). If a host shift occurs, hybrid offspring of individuals that use different hosts may experience lower fitness on either host species, resulting in ecologically dependent post-zygotic isolation (Rundle \& Nosil 
2005). Additionally, if the symbiont exhibits high host fidelity, then shifting to a new host can directly cause pre-zygotic barriers between parental and daughter populations (Feder et al. 1994). Even though host shifts could significantly reduce gene flow among subpopulations, the process is gradual and may not always lead to complete reproductive isolation. Depending on the levels of gene flow, individuals occupying different host species could represent within-species polymorphisms (panmixis), host races (restricted gene flow), or true species (no gene flow) (Drès \& Mallet 2002; Peccoud et al. 2009). Host races are defined as genetically differentiated sympatric populations that show high levels of host fidelity, but experience at least some gene flow (Drès $\&$ Mallet 2002). Their formation is both an intermediate step and a prerequisite for host-mediated speciation (Berlocher \& Feder 2002; Peccoud et al. 2009).

Host races have been reported mostly from parasitic and phytophagous organisms in terrestrial systems (Berlocher \& Feder 2002). Relatively few studies have been done on marine taxa, even though symbiotic associations such as commensalism are not rare in marine environments (Anker et al. 2005). Studies on sponge-dwelling alpheid shrimps and bivalve-associated pea crabs have revealed high degrees of host-specific genetic and phenotypic structuring (Stevens 1990; Duffy 1996), suggesting that host shift-driven diversification in marine commensal species may be relatively common. To test if this ecological speciation mechanism has played a role in galeommatoidean diversification, one possible strategy is to look for evidence of host race formation in commensal species with multiple hosts.

To date, there has only been one such study. Sato et al. (2011) attempted to distinguish populations of a commensal galeommatoid, Koreamya arcuata (ADAMs 1856), from two congeneric lingulid brachiopod hosts. They found subtle morphological differences between members of the two populations, but failed to detect host-specific genetic structuring. This is perhaps not very surprising because the two hosts are very similar in their biology and ecology, and the commensals are therefore less likely to be under strong divergent selection. A more rigorous test of the host-shift diversification hypothesis would involve commensal species with very different host species, thereby providing more opportunities for divergent selection to occur.

Neaeromya rugifera (CARPENTER 1864) (Fig. 1) is a Northeastern Pacific commensal species distributed from Alaska to Lower California (Coan et al. 2000). It is associated with two strikingly different
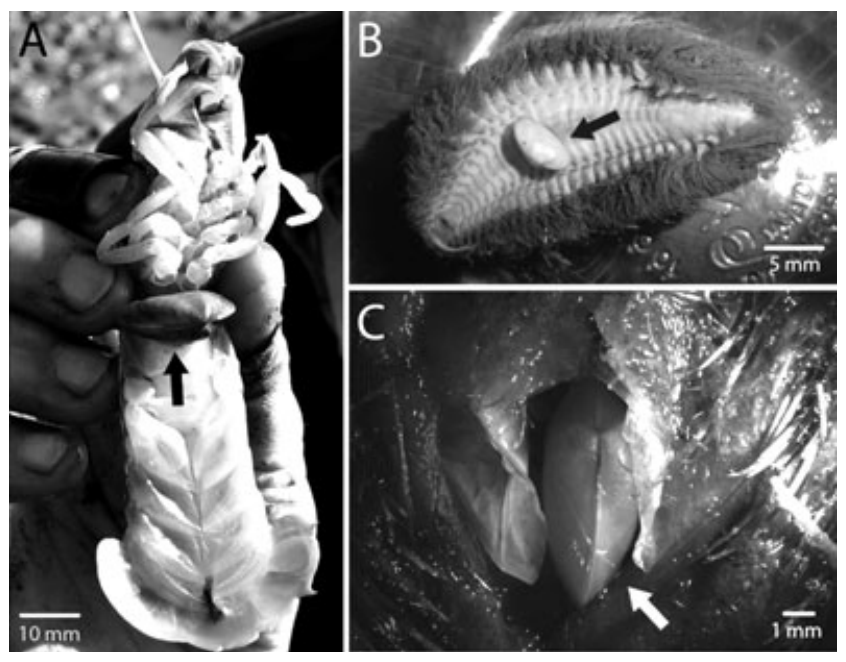

Fig. 1. The commensal galeommatoidean clam Neaeromya rugifera on its hosts. A. A clam (black arrow) attached to the ventral surface of the blue mud shrimp, Upogebia pugettensis. B. A clam (black arrow) attached to the ventral surface of the sea mouse Aphrodita sp. C. A clam (white arrow) inside the respiratory cavity of the sea mouse Aphrodita sp. The clam was revealed by cutting open the dense "felt" covering the dorsal surface of the worm. Photo in $\mathrm{C}$ by L. Kirkendale.

hosts that are sympatrically distributed: the blue mud shrimp Upogebia pugettensis (DANA 1852) and the polychaete worm Aphrodita spp. (Due to taxonomic uncertainty, it is unclear if $N$. rugifera is associated with one or multiple species in the genus Aphrodita [C. Brantley, pers. comm.]; thus, we refer to sea mouse host as Aphrodita spp. in this study.) The two hosts are very different in their morphology and ecology. Upogebia pugettensis is a thalassinid shrimp that builds deep, permanent Y-shaped burrows in intertidal mudflats in estuaries (Dumbauld et al. 2011). The genus Aphrodita includes broadbodied polychaetes, commonly known as sea mice, that burrow just below the surface of subtidal muddy bottoms (Carlton 2007). Neaeromya rugifera attaches to the ventral surface of both hosts by byssal threads (Fig. 1A,B), but it also occurs in the respiratory cavity of Aphrodita spp. (Narchi 1969; Ó Foighil 1985) (Fig. 1C).

Members of Neaeromya rugifera are protandric hermaphrodites. A large female individual typically houses one or more dwarf males in her mantle cavity; thus, mating and fertilization occur only on the host. The female broods fertilized eggs, then releases the larvae, which undergo planktotrophic development (Ó Foighil 1985). Given that members of $N$. rugifera occur on two dramatically different hosts, it seems plausible that populations have 
developed specialized morphological or behavioral adaptations to each host and that genetically distinct host races have been formed in this species. Alternatively, it is also possible that individuals respond to different host types via phenotypic plasticity and represent a panmictic population. Here, we tested the hypothesis that host races are present in this species.

\section{Methods}

An ideal test of our hypothesis would involve raising veliger larvae from clams associated with the two hosts and then testing the host preferences of larvae and juveniles. Host fidelity can be confirmed if larvae or juveniles always prefer the host species that their parents were associated with. However, such experiments are impractical, as it is extremely challenging to raise and track pelagic larvae, as well as to maintain the two host species under artificial environments in the laboratory. Instead, we sampled specimens of Neaeromya rugifera from both Upogebia pugettensis and Aphrodita spp. and tested for host-specific morphologies and genetic structuring.

\section{Collections}

A total 35 individuals of $N$. rugifera were collected from $U$. pugettensis, and seven individuals from Aphrodita spp. The sampling process, which was carried out $>3$ years, was very challenging due to difficulties in collecting members of the host species, and the low incidence of clams on hosts. Upogebia pugettensis is currently experiencing a dramatic population decline, likely due to an introduced isopod parasite; several previously abundant populations from estuaries in California have been reported as locally extinct, and populations in Washington and Oregon are collapsing rapidly (Dumbauld et al. 2011). Therefore, we were restricted to one sampling location in Yaquina Bay, Newport, Oregon, where the shrimps were still relatively abundant in 2009. Shrimps were collected from their borrows using a yabbie pump. The clams were detached from hosts and deposited in the Museum of Zoology, University of Michigan (UMMZ 302939). Sea mouse commensals were even more difficult to obtain because hosts are subtidal and uncommon. To search for the commensals, the first author joined several dredging trips conducted by the Friday Harbor Laboratories (FHL) off of San Juan Island, WA, and the Sanitation Districts of Los Angeles County (LACSD) off of San Pedro, CA. In addition, the authors requested that specimens of $\mathrm{Aph}$ - rodita spp. be collected for them by these and other institutions that perform regular dredging activities. These efforts yielded only $\sim 11$ freshly collected specimens of Aphrodita spp., none of which bore commensal clams. We were thus restricted to old samples previously collected and preserved by the California Academy of Sciences (CASIZ 85863, collected from Puget Sound, WA, USA, in 1924, formalin fixed), the Royal British Columbia Museum (990-00393-008, collected from Moresby Island, BC, Canada, in 1978, formalin fixed), the Shannon Point Marine Center (UMMZ 302992, collected from Anacortes, WA, USA, in 2009, preserved in $75 \%$ ethanol), and LACSD (UMMZ 302993, collected from San Pedro, CA, USA, in 2008, preserved in 95\% ethanol; and UMMZ 302994, collected from San Pedro, CA, USA, in 2000, formalin fixed).

\section{Morphometric analyses}

Shell morphologies of the clams from the two host species were compared using a geometric morphometric approach (Zelditch et al. 2004). The external lateral view of the right valve of each individual was photographed using a Leica DFC320 digital camera system (Leica Microsystems, Wetzlar, Germany), and images processed with Image-Pro Discovery 5.1 (Media Cybernetics, Silver Spring, MD, USA). Because bivalve shells usually lack informative homologous points for landmark placement, we treated shell shapes as curves and adopted a semi-landmark approach (Bookstein 1997). One hundred semi-landmarks were evenly placed along the shell outline of each specimen using the software tpsDig2 (Rohlf 2010) to capture the overall shell shape. Semi-landmarks were slid following the minimum bending energy criterion (Bookstein 1997) in tpsRelw 1.49 (Rohlf 2010) to ensure shape homology among individuals. Shape coordinates of all specimens were then superimposed using the Procrustes method (Rohlf \& Slice 1990) implemented in CoordGen7a (Sheets 2011) to remove variation caused by differences in shell size, position, and orientation. Canonical variate analysis (CVA) was performed in CVAgen7b (Sheets 2011) on the shape coordinates to test whether shell shapes of the two groups are significantly different (PCA reduction was used to account for small sample size). The first canonical variate (CV1) scores were plotted using $\mathrm{R}$ 2.12 (R Development Core Team 2011). A deformation grid presenting vector on landmarks was generated in CVAgen $7 \mathrm{~b}$ to show how general shell shape changes along CV1. A Jackknife grouping test was performed in CVAgen 7b to cross validate the group- 
ing procedure. In the test, each specimen was left out in turn, and the CVA was done on the remaining $\mathrm{n}-1$ specimens. The $\mathrm{CV}$ axis derived from the analysis was then used to assign the left-out specimen to one of the groups. This was done for all specimens. A classification table was generated to present the results.

\section{Molecular analyses}

The mitochondrial cytochrome oxidase I (COI) gene segment was examined to identify population genetic structure in $N$. rugifera. A small piece of mantle tissue from each specimen was used for genomic DNA extraction using the Omega Biotek E.Z.N.A. Mollusc DNA Kit (Omega Bio-Tek, Norcross, GA, USA). The target gene was amplified from the freshly sampled shrimp commensals using universal primers LCO1490/HCO2198 (Folmer et al. 1994), following a touchdown PCR protocol. The initial annealing temperature was $55^{\circ} \mathrm{C}$; it was decreased by $2^{\circ} \mathrm{C}$ per cycle until the final annealing temperature $\left(45^{\circ} \mathrm{C}\right)$ was reached, and then the reaction was continued for an additional 40 cycles. However, this combination of parameters did not successfully amplify DNA from any of the formalin- and ethanol-preserved museum sea mouse commensal specimens, presumably due to suboptimal DNA template quality. To surmount this technical difficulty, a doubly nested amplification procedure was developed. The first round of PCR was performed as above using the universal primers to slightly increase the amount of template DNA, to improve the success rate of the subsequent, nested PCR. Products from the first PCR were then used as templates for a second round of touchdown PCR using a novel internal primer set (17N2: 5'-CG TTATTGTGACTGCTCATGC-3'; 18N1： 5'-GCA TAGTGATAGCACCAGC-3') designed from shrimp commensal sequences. Negative controls (PCR cock- tails without DNA templates) were used during every amplification to test for contamination. All PCR products were directly sequenced at the University of Michigan Sequencing Core. Sequences were aligned using ClustalW (Thompson et al. 1994) implemented in CodonCode Aligner 3.1.7 (CodonCode Corporation, Dedham, MA, USA), and corrected by eye. COI gene segments amplified from the shrimp commensals had a length of $658 \mathrm{bp}$, but those from sea mouse commensals were shorter ( $420 \mathrm{bp}$ ) due to the use of internal primers. Comparative analyses among both sets of commensal clams used the homologous $420 \mathrm{bp}$ fragment. A parsimony network of all haplotypes was constructed using TCS 1.21 (Clement et al. 2000) to visually represent genetic structuring of the sampled clams.

\section{Results}

The CVA of shells of Neaeromya rugifera showed that clams from the two hosts represent two distinct groups; the difference was highly significant $(p<0.001)$ (Fig. 2). The two groups occupied distinct regions in the morphospaces, with no overlap. The Jackknifed grouping test showed that 34 of 35 shrimp commensals and five of seven sea mouse commensals were placed in the correct CVA group (93\% correct assignments). The vector on landmarks grid indicated that major morphological change along CV1 occurred on the shell ventral margin. Specifically, the ventral margin of individuals collected from the shrimp host showed a distinctive inward curvature, which was completely lacking on individuals collected from the sea mouse host. We did not identify significant differences in shell form between individuals that attached to the ventral surface $(N=6)$ or the respiratory cavity $(N=1)$ of sea mice.
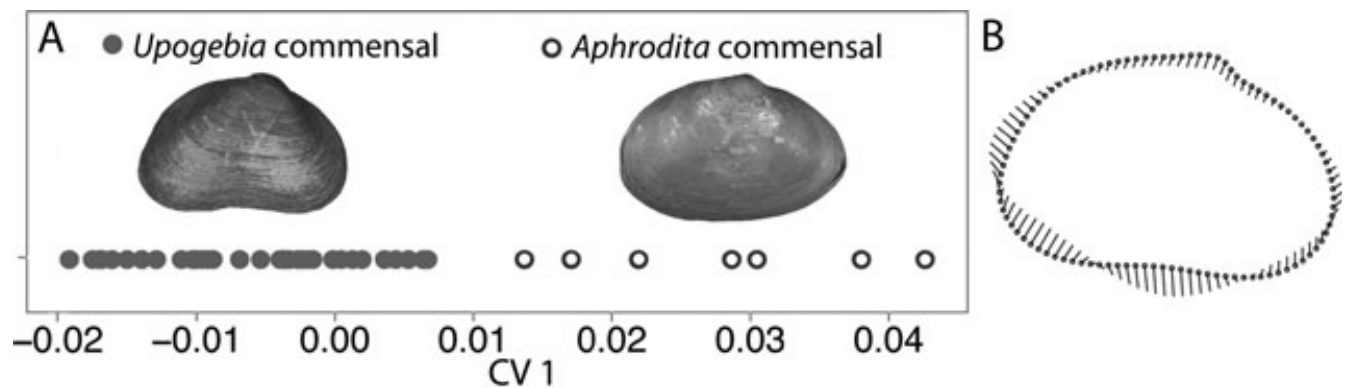

Fig. 2. Canonical variate analysis (CVA) on shell shape of individuals of Neaeromya rugifera from two host species. A. Scatter plot of CV1 scores of all specimens. Solid and hollow circles represent specimens from each host species. B. Vectors on landmarks showing how shell shape changes along CV1, representing how shell shape changes from a shrimp commensal type to a sea mouse commensal type. 
Sequences from 27 shrimp commensals (GenBank accession numbers JQ712843-69) and three sea mouse commensals (JQ712840-42) were successfully amplified. The low sequence recovery rate from the sea mouse commensals was mainly due to poor template quality. From the haplotype network (Fig. 3), we did not detect strong evidence for genetic differentiation (with the caveat that our sea mouse commensal sample size is low, and that faster-evolving markers might yield a different result). The same haplotype was the most common in both sets of commensals, and haplotypes did not cluster according to either host type or geographic location. Among the three sea mouse commensal specimens that were successfully genotyped, two were directly preserved in ethanol and one was formalin fixed. One of the ethanol-preserved specimens (from San Pedro, CA, collected in 2008) had a unique COI haplotype that differed from a shrimp commensal haplotype by two inferred nucleotide substitutions. The other ethanol-preserved specimen (Anacortes, WA, 2009), together with the formalin-fixed specimen (San Pedro, CA, 2000), exhibited the most common haplotype. Due to the sensitive nature of PCR reactions, there is a risk that the sequence amplified from the formalin-fixed individual may

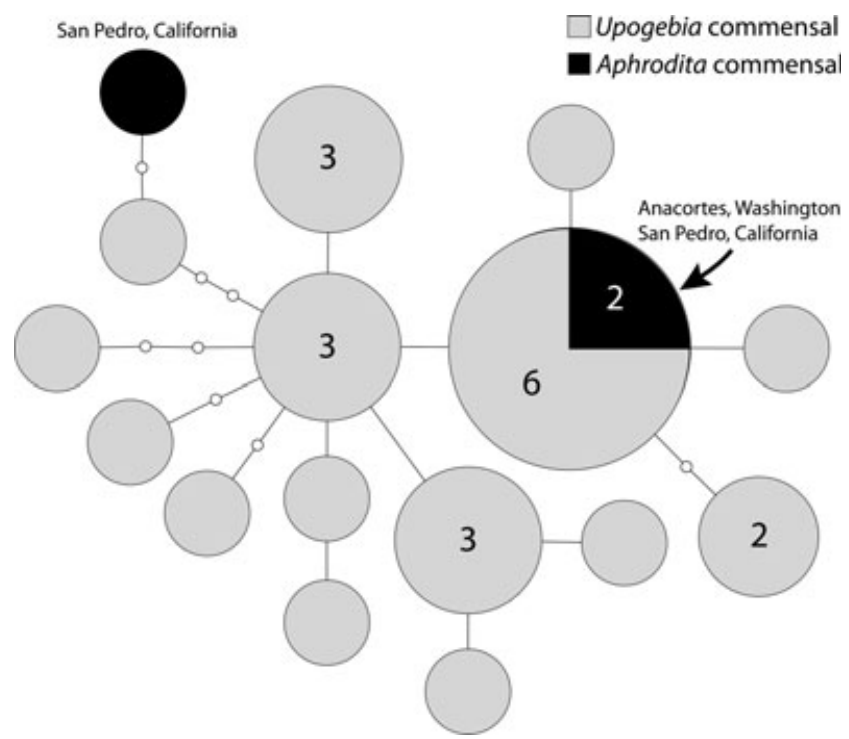

Fig. 3. COI haplotype network showing genetic structuring of Neaeromya rugifera collected from two host species. Each circle represents a unique haplotype. Circle diameter represents how many specimens share the same haplotype, as do numbers in circles (only present if that haplotype was found more than once). Each connection represents one inferred base pair change. All shrimp commensals are from Newport, Oregon. Localities for the sea mouse commensals are indicated by labels. actually come from trace contamination from shrimp commensals, despite the absence of evidence for such in our negative controls. However, even taking this possibility into account, the main pattern of haplotype distribution does not change.

\section{Discussion}

Our results reject the hypothesis that host races have been formed in Neaeromya rugifera. Despite strong morphological distinction, the lack of hostspecific genetic structuring suggests that the populations are panmictic and that host fidelity has not yet been established. The host-specific shell morphologies most likely represent ecophenotypic plasticity rather than incipient speciation. Ecophenotypic variation in shell morphology is not rare in bivalves (Valladares et al. 2010). Because individuals of $N$. rugifera attach to their hosts directly, it is possible that the shell developmental processes are affected by the texture and shape of the attachment surfaces. The shrimp has a relatively hard, smooth exoskeleton, and its ventral abdomen surface is narrow and slightly convex, whereas the sea mouse represents a soft, broad, and relatively flat attachment surface. Therefore, shrimp commensals may need to produce more or stronger byssal threads to establish a stable association with the host, and a curvature on the ventral margin of the shell could form gradually around the attachment point during shell growth. Massive byssal thread production may not be necessary for sea mouse commensals to form a stable attachment, especially for the individuals that settled inside the host's respiratory cavity; thus, their shell growth may be less influenced by the byssal attachment point.

Given the disparity in its host taxa, it is a little surprising that evidence for host races was not observed in $N$. rugifera. Two factors may help explain this result. First, this species undergoes obligate planktotrophic larval development (O Foighil 1985). For a host shift to directly impose rapid prezygotic isolation, newly metamorphosed juveniles must display fidelity to the new host when re-establishing the benthic commensal association. This critical condition could be hard to meet when organisms exhibit long-range dispersal. Second, a generalist strategy may possess selective advantages compared with a specialist one in this group. Because the commensal lifestyle for most galeommatoidean clams is obligate, flexibility in using hosts will protect them from host extinction events, even though it requires the larvae or juveniles to recognize multiple host species. The ongoing collapse of populations of 
Upogebia pugettensis is perhaps a vivid example. Without its second host Aphrodita spp., N. rugifera might be greatly threatened.

A congeneric species, $N$. compressa (DALl 1899), has a distribution that largely overlaps with that of $N$. rugifera (Coan et al. 2000). This species has only been recovered through dredging, and although it is suspected to be a commensal of burrowing invertebrates (Coan et al. 2000), no confirmed host association has been identified to date. Neaeromya compressa is morphologically similar to $N$. rugifera (especially to the sea mouse commensals, because it lacks a ventral curvature), but it is taxonomically distinguished from the latter by a more flattened and compressed shell form (Dall 1899; Coan et al. 2000). Given the high degree of phenotypic plasticity displayed by $N$. rugifera, it is possible that shell form of $N$. compressa falls within the shape spectrum of the shell of $N$. rugifera and may not represent a species-level diagnostic character. However, to further investigate the relationships of $N$. rugifera and $N$. compressa, one would need to quantitatively examine the shell morphology (particularly inflation) of the two species, and to incorporate genetic analyses.

In conclusion, although $N$. rugifera occupies two drastically different host species and exhibits distinct host-specific shell phenotypes, we did not detect evidence of host race formation. Instead, the results indicate that $N$. rugifera possesses a high degree of developmental and behavioral plasticity that enables the larvae or juveniles to recognize (possibly through chemical cues) two distinct benthic host species, and to form stable physical associations with them. This study of $N$. rugifera, along with previous works (Sato et al. 2011), suggests that speciation by host shift may not be a major diversification mechanism in Galeommatoidea. However, our results need to be further corroborated by studies of additional commensal species associated with distinct hosts.

Acknowledgments. The authors thank John Chapman, Don Cadien, Cheryl Brantley, and Gustav Paulay for their assistance during fieldwork, and Brian Bingham, David Cowles, Christina Piotrowski, and Moretta Frederick for generously providing specimens to support this study. We thank Miriam Zelditch for providing expertise in the morphometric analysis. Three anonymous reviewers and editor Greg Rouse helped to improve the quality of the manuscript. This study was funded by a Melbourne R. Carriker Student Research Award in Malacology from the American Malacological Society and a Department of Ecology and Evolutionary Biology Block
Grant (both to J. Li) and NSF OCE award 0850625 (to D. Ó Foighil).

\section{References}

Anker A, Murina GV, Lira C, Caripe JAV, Palmer AR, \& Jeng MS 2005. Macrofauna associated with echiuran burrows: a review with new observations of the innkeeper worm, Ochetostoma erythrogrammon Leuckart and Rüppel, in Venezuela. Zool. Stud. 44: 157-190.

Berlocher SH, \& Feder JL 2002. Sympatric speciation in phytophagous insects: moving beyond controversy? Annu. Rev. Entomol. 47: 773-815.

Bookstein FL 1997. Landmark methods for forms without landmarks: localizing group differences in outline shape. Med. Image Anal. 1: 225-243.

Boss KJ 1965. Symbiotic erycinacean bivalves. Malacologia 3: 183-195.

Bouchet P, Lozouet P, Maestrati P, \& Heros V 2002. Assessing the magnitude of species richness in tropical marine environments: exceptionally high numbers of molluscs at a New Caledonia site. Biol. J. Linn. Soc. 75: $421-436$.

Carlton JT, ed. 2007. The Light \& Smith Manual: Intertidal Invertebrates from Central California to Oregon, 4th Edition. University of California Press, Berkeley, California. 1001 pp.

Clement M, Posada D, \& Crandall KA 2000. TCS: a computer program to estimate gene genealogies. Mol. Ecol. 9: 1657-1660.

Coan EV, \& Valentich-Scott P 2012. Bivalve Seashells of Tropical West America - Marine Bivalve Mollusks from Baja California to Northern Perú. Santa Barbara Museum of Natural History Press, Santa Barbara, California. 1258 pp.

Coan EV, Valentich-Scott P, \& Bernard FR 2000. Bivalve Seashells of Western North America. Santa Barbara Museum of Natural History Press, Santa Barbara, California. 764 pp.

Dall WH 1899. Synopsis of the recent and tertiary Leptonacea of North America and the West Indies. Proc. U. S. Nat. Mus. 21: 873-897.

Drès M \& Mallet J 2002. Host races in plant-feeding insects and their importance in sympatric speciation. Philos. Trans. R. Soc. Lond. B. 357: 471-492.

Duffy J 1996. Species boundaries, specialization, and the radiation of sponge-dwelling alpheid shrimp. Biol. J. Linn. Soc. 58: 307-324.

Dumbauld B, Chapman J, \& Torchin M 2011. Is the collapse of mud shrimp (Upogebia pugettensis) populations along the Pacific Coast of North America caused by outbreaks of a previously unknown bopyrid isopod parasite (Orthione griffenis)? Estuar. Coast. 34: 336350.

Feder JL, Opp SB, Wlazlo B, Reynolds K, Go W, \& Spisak S 1994. Host fidelity is an effective premating barrier between sympatric races of the apple maggot fly. Proc. Natl. Acad. Sci. USA 91: 7990-7994. 
Folmer O, Black M, Hoeh W, Lutz R, \& Vrijenhoek R 1994. DNA primers for amplification of mitochondrial cytochrome c oxidase subunit I from diverse metazoan invertebrates. Mol. Marine Biol. Biotechnol. 3: 294 297.

Jespersen Å, Lützen J, \& Nielsen C 2004. On three species and two new genera (Montacutella and Brachionlya) of galeommatoid bivalves from the irregular sea urchin Brissus latecarinatus with emphasis on their reproduction. Zool. Anz. 243: 3-19.

Mikkelsen PM \& Bieler R 1989. Biology and comparative anatomy of Divariscintilla yoyo and D. troglodytes, two new species of Galeommatidae (Bivalvia) from stomatopod burrows in eastern Florida. Malacologia 31: 175-195.

Morton B \& Valentich-Scott P 1989. The Hong Kong Galeommatacea (Mollusca: Bivalvia) and their hosts, with descriptions of new species. Asian Mar. Biol. 6: 129-160.

Narchi W 1969. On Pseudopythina Rugifera (Carpenter, 1864) (Bivalvia). Veliger 12: 43-52.

Ó Foighil D 1985. Form, function, and origin of temporary dwarf males in Pseudopythina rugifera (Carpenter, 1864) (Bivalvia: Galeommatacea). Veliger 27: 245-252.

Paulay G 2003. Marine bivalvia (Mollusca) of Guam. Micronesica 35-36: 218-243.

Peccoud J, Ollivier A, Plantegenest M, \& Simon JC 2009. A continuum of genetic divergence from sympatric host races to species in the pea aphid complex. Proc. Natl. Acad. Sci. USA 106: 7495-7500.

R Development Core Team 2011. R: A language and Environment for Statistical Computing. Vienna, Austria.

Reznick DN \& Ghalambor CK 2001. The population ecology of contemporary adaptations: what empirical studies reveal about the conditions that promote adaptive evolution. Genetica 112-113: 183-198.

Rohlf FJ 2010. TPS Series Software for Morphometric Analysis. Department of Ecology and Evolution, State University of New York at Stony Brook, Stony Brook, New York.

Rohlf FJ \& Slice DE 1990. Extensions of the Procrustes method for the optimal superimposition of landmarks. Syst. Zool. 39: 40-59.
Rundle H \& Nosil P 2005. Ecological speciation. Ecol. Lett. 8: 336-352.

Sato S, Owada M, Haga T, Hong JS, \& Yamashita JLH 2011. Genus-specific commensalism of the galeommatoid bivalve Koreamya arcuata (A. Adams, 1856) associated with lingulid brachiopods. Molluscan Res. 31: 95-105.

Schneider S, \& Hochleitner R 2006. Great diversity in small space - a remarkable bivalve association from the Lower Pliocene of Harokopio (SW Peloponnesus, Greece). In: International Congress on Bivalvia (23.07. -27.07.2006) - Scientific Program and Abstracts. Malchus N \& Pons JM, eds., pp. 72. Universitat Autònoma de Barcelona, Barcelona, Spain.

Sheets HD 2011. Integrated Morphometrics Package. Department of Physics, Canisius College, Buffalo, New York.

Simon JC, Carre S, Boutin M, Prunier-Leterme N, Sabater-Muñoz B, Latorre A, \& Bournoville R 2003. Hostbased divergence in populations of the pea aphid: insights from nuclear markers and the prevalence of facultative symbionts. Proc. R. Soc. Lond. B Biol. Sci. 270: 1703-1712.

Stevens PM 1990. A genetic analysis of the pea crabs (Decapoda: Pinnotheridae) of New Zealand. I. Patterns of spatial and host-associated genetic structuring in Pinnotheres novaezelandiae Filhol. J. Exp. Mar. Biol. Ecol. 141: 195-212.

Thompson JD, Higgins DG, \& Gibson TJ 1994. CLUSTAL W: improving the sensitivity of progressive multiple sequence alignments through sequence weighting, position specific gap penalties and weight matrix choice. Nucleic Acids Res. 22: 4673-4680.

Valladares A, Manríquez G, \& Suárez-Isla BA 2010. Shell shape variation in populations of Mytilus chilensis (Hupe 1854) from southern Chile: a geometric morphometric approach. Mar. Biol. 157: 2731-2738.

Zelditch ML, Swiderski DL, Sheets HD, \& Fink WL 2004. Geometric Morphometrics for Biologists: a Primer. Elsevier Press, New York. 443 pp. 